\title{
RELATIONSHIP BETWEEN COGNITIVE RESERVE, MOTOR RESERVE AND THALAMUS VOLUMETRY IN OLDER ADULTS
}

\author{
Anete Šneidere-Šustiṇa \\ Rīga Stradiņš University, Latvia \\ Kristīne Šneidere \\ Rīga Stradiņš University, Latvia \\ Nicholas G. Dowell \\ University of Sussex, UK \\ Ainārs Stepens \\ Rīga Stradin̄š University, Latvia
}

\begin{abstract}
With the increasing worldwide population, an ongoing escalation in mild cognitive impairment and dementia is predicted. Motor reserve - the cumulative physical activity experience gained throughout life, as well as cognitive reserve - the brain's ability to overcome a pathology, such as neurodegenerative disorders, - has been identified as protective factors in cognitive decline. Thus, this study aimed to investigate the relationship between cognitive reserve, motor reserve, and brain volumetry in older adults. 44 older adults $(M=70, S D=$ $5.18,77.3 \%$ female) with no self-reported significant neurological, ongoing oncological etc. disorders that might limit their participation in the study were involved in the study. All participants underwent a thorough life-style and psychological assessment, as well as structural brain MRI analysis. Overall, our study indicated the significance of a combination of lifestyle factors in predicting thalamic volume. The results of this study indicate that life-long participation in physical, intellectual, and social activities could be beneficial for preserving the volume of thalamus, which is among the first to decline due to aging. Keywords: cognitive reserve, motor reserve, thalamus.
\end{abstract}

\section{Introduction}

Evaluating the data available from World Report on Ageing and Health the proportion of people aged 60 years and older in Europe varied between 20-29\% in 2015. In comparison with, for example, the USA and Canada the numbers fluctuated between 20 to $24 \%$. The predicted percentage in the year 2050 in Europe is around $30 \%$, while in Canada and the USA it is expected to increase to $25-29 \%$. There is a visible tendency for a proportional rise which can be associated with better survival rates in early childhood in lower-income countries 
and increasingly superior quality of healthcare in developed countries (WHO, 2015). With the age being the most significant risk factor for developing a neurodegenerative disease, the Alzheimer's Disease International predicts around 9.9 million new Alzheimer's disease (AD) patients worldwide yearly, or, in other words, one new patient every 3.2 seconds, making the yearly burden of the disease 604 billion USD in 2010 and 818 billion USD in 2015 (WAR, 2015). There has been an extensive amount of predictive research that strives to mathematically anticipate the burden of Alzheimer's Disease (AD) to the world in the near future. According to Brookmeyer et al. (2007), there were 26.6 million people worldwide living with this condition in year 2007 and the predicted prevalence was 1:85 or 106.2 million in year 2050 that is directly associated with the increase not only in the overall population but the geriatric population as well.

Considering the significant increase in the aging population and its increased risk for $\mathrm{AD}$, identifying factors contributing to the disease progression, as well as finding pharmaceutical and life-style cure, is essential. Recent studies indicate the effectiveness of prevention (or prophylaxis) of the disease. Primary prophylaxis aims to reduce the risk of dementia before its biological onset, whilst secondary prophylaxis aims to manage early diagnostics before the occurrence of symptoms (Pudule et al., 2010). When focusing on primary prophylaxis, an understanding of modifiable and unmodifiable risk factors is necessary. Unmodifiable AD risk factors are, for example, genetic (APOE-4, GNG4, KCNQ2) (Šneidere et al., 2019), as well as aging, gender, lack of early education, inborn physical attributes, traumas, etc. Modifiable risk factors to consider are vascular and lifestyle with hypertension and hyperlipidaemia being the most commonly analysed. An increasing amount of research indicates that lifestyle factors could play an important role in the way we grow older (Bherer, Erickson, \& Liu-Ambrose, 2013).

Three major lifestyle factors have been thought to have a significant role in slowing the rate of cognitive decline as well as preventing dementia amongst people with both positive and negative family history of Alzheimer's disease one of them being regular physical activity (Frith \& Loprinzi, 2017).

Physical activity is any skeletomuscular movement that results in energy expenditure (Caspersen, Powell, \& Christenson, 1985). Interest in the effects of physical activity on cognition, peaked as long ago, as the 1970s, when Waneen Wyrick Spirduso, a researcher from the University of Texas, published a systematic review on the relationship between physical activity and reaction and movement time (Spirduso, 1975). The relevance of this review increased with the findings in the studies by Kramer and Colcombe, showing an increase in the frontal cortex after an aerobic physical activity intervention (Colcombe et al., 2006). The concept was further developed by other researchers, identifying further and more detailed associations between aerobic activity and such brain 
structures as the hippocampus (Prakash, Snook, Motl, \& Kramer, 2010), the thalamus (Erickson et al., 2011), as well as the amygdala (Boots et al., 2015). A meta-analysis by Biazus-Sehn et al. (2020) confirms that physical activities could positively affect cognitive function during ageing process, preventing or at least delaying the MCI progression to Alzheimer's disease. This could be through changes in molecular and/or cellular pathways such as reduction of TNF- $\alpha$ and Il-6 as well as an increase of BDNF and larger-scale changes as increased blood flow to the brain and neovascularization and as a consequence making changes in the neurovascular system, molecular cascades and therefore promoting neurogenesis and synaptic plasticity.

However, while the studies do indicate the significance of short-term interventions, studies considering the role of long-term physical activity, are still lacking. Jeremy Young, a doctoral student at the time, at the University of Sussex, investigating the brain volumetric differences between sports veterans and socially active older adults, conducted one such study, however, showing no differences between the two groups (Young et al., 2016). We aimed to replicate the study; however, chose not to divide the participants into two groups, but consider the overall physical activity experience over the years as physical activity is a complex phenomenon (see definition above). To distinguish it from the commonly used term "physical activity", the term "motor reserve" was defined and will be used further in this article.

While the motor reserve is a relatively unknown term, the cognitive reserve has been well known for the past twenty years and is defined as "the adaptability (i.e., efficiency, capacity, flexibility) of cognitive processes that helps to explain differential susceptibility of cognitive abilities or day-to-day function to brain aging, pathology, or insult (Stern et al., 2018, p. 2). Significant studies have been conducted to research the association between functional and volumetric characteristics of the brain, e.g. a study conducted by Speer and Soldan (2015), showed that higher cognitive reserve was associated with better neural efficiency. In the meta-analysis by Bartres-Faz et al. (2011) not only an impact on brain structural parameters was noted contributed by the cognitive reserve, but it was also concluded that the effects might be regionally specific. However, more studies identifying the role of cognitive reserve in mediation between the structural damage of the brain and cognitive processes (e.g. see Rocca et al., 2018) are needed.

As most of the research regarding physical activity and cognitive reserve has mainly been focused on the short term physical activity interventions, our objective was to identify the relationship between the effects of motor reserve, cognitive reserve as well as brain volumetric measures in older adults. 


\section{Methodology}

Participants. Forty-four participants aged 65 to $86(M=70.00, S D=5.18$, $77.3 \%$ female) were recruited for the study. Participants reported being nonsmokers for at least past 5 years, have been on stable or no medication during the past 12 months and with Latvian proficiency of a native speaker, as well as with no self-reported diagnosis of memory dysfunction, cardiovascular disease, ongoing oncological or psychiatric disease, neurological deficiencies or other factors that might limit their participation in the study (e.g. metallic implants or cardiostimulators). Whilst screening the data, 3 participants were rejected due to not complying with the inclusion criteria or due to missing data.

Cognitive reserve assessment. The cognitive reserve were assessed using The Cognitive Reserve Index questionnaire (CRIq, Nucci, Mapelli, \& Mondini, 2012). This questionnaire consists of three subscales: education (comprised of formal and vocational studies), working activity (measured in five levels, based on the level of responsibility and education requirements), and leisure activities (including weekly, monthly, annual and fixed activities).

Motor reserve assessment. Firstly, the data on physical activity were obtained, using the physical activity scale of the Social Determinants of Health Behaviours questionnaire (FINBALT, 2008). From this questionnaire a year grade was collected, further, a median was obtained from the grade category. The motor reserve index was calculated based on cumulative time dedicated to aerobic exercise over the years (since the age of 15), divided by maturity years.

MRI measures. Images were acquired using Siemens 1.5 Tesla Avanto MRI scanner (Siemens, Erlangen, Germany). High-resolution anatomical images were acquired using a three-dimensional T1-weighted magnetization prepared rapid acquisition gradient echo (MPRAGE) sequence [TR=1160 ms, TE=4.44 ms; inversion recovery time $(\mathrm{TI})=600 \mathrm{~ms}$; field of view, $230 \times 230 \mathrm{~mm}^{2}$; matrix size 256 x 256; flip angle $\theta=15$ degrees; voxel dimensions, $0.9 \times 0.9 \mathrm{~mm}^{3}$; acquisition time, $5 \mathrm{~min}]$.

Procedure. Data were obtained with each participant individually. Firstly, all participants were introduced to the aims, risks, and benefits of the study and signed an informed consent. Further, as part of cognitive assessment, cognitive reserve indices were obtained, followed by an MRI analysis at Pauls Stradiňs Clinical University Hospital. Finally, physical activity assessment was conducted. It should be noted that the data reported in this article, are part of a larger data set obtained under State Research Programme BIOMEDICINE, sub-project No. 5.8.2., thus the procedure included additional assessments, not reflected in the article.

Statistical analysis. Statistical analysis was performed using IBM SPSS Statistics 26. In the first step, data screening was performed, during which 3 
participants were discarded. Acquired data did not match the Gaussian distribution, therefore Spearman's Rank Correlation was used. To exclude the effects of different cranial sizes, as suggested by O’Brien et al., 2012, a regression-based approach was chosen, using the intracranial volume as a confounding variable in the hierarchical multiple regression analysis. It should be noted that, while O'Brien et al. discussed ANCOVA in their article, only continuous data were used in this study, thus hierarchical regression model was chosen

\section{Results}

To determine the method of statistical analysis, compliance with normal distribution was calculated, indicating the need to use non-parametric methods ( $\mathrm{p}$ $<.05)$. Next, a central tendency indicator $(M d n)$ of participants' age, motor reserve, cognitive reserve, and its' subindices, as well as brain volumetry, were calculated (see Table 1).

Table 1 Median Indicators of Demographic Data, Brain Volumetric Measure, Cognitive Reserve Measures, and Motor Reserve

\begin{tabular}{|c|c|}
\hline Variable & Mdn \\
\hline Age & 70 \\
\hline Motor reserve & 0.53 \\
\hline Cognitive reserve total (CRI) & 132.00 \\
\hline CRI-Education & 120.45 \\
\hline CRI-Occupation & 118.00 \\
\hline CRI-Leisure & 132.20 \\
\hline Thalamus (TV) & 12650.95 \\
\hline Thalamus - Right & 6147.1 \\
\hline Thalamus - Left & 6537.7 \\
\hline
\end{tabular}

Note. CRI - cognitive reserve index, TV - total volume, WB - whole

A hierarchical multiple regression analysis was run to determine if the addition of the estimated total intracranial volume (eTIV) as a cofound variable improved the prediction of the thalamus laterally and bilaterally.

The full model of motor reserve, education, occupation, leisure, and eTIV to predict the volume of the left side of the thalamus (Table 2) was statistically significant $\left(R^{2}=.34, F(5,38)=3.98, p<.05\right)$. The addition of education to the prediction of volume of left the side of the thalamus led to a statistically insignificant increase in $R^{2}$ of .01, $F(1,41)=.50, p>.05$. The addition of occupation to the previous model (Model 3) also led to an insignificant increase of $R^{2}$ of .02, $F(1,40)=.93, p>.05$. 
Šneidere-Šusting et al., 2021. Relationship Between Cognitive Reserve, Motor Reserve and Thalamus Volumetry in Older Adults

Table 2 Hierarchical Multiple Regression Predicting Volume Of Left Side Of Thalamus From Motor Reserve, Education-CRI, Occupation-CRI, Leisure Time-CRI, eTIV

\begin{tabular}{|c|c|c|c|c|c|}
\hline \multicolumn{2}{|c|}{ Thalamus-Left } & $\beta$ & $R^{2}$ & $F$ & $\Delta R^{2}$ \\
\hline Model 1 & Motor reserve & .23 & .05 & 2.28 & .05 \\
\hline Model 2 & $\begin{array}{l}\text { Motor reserve } \\
\text { Education-CRI }\end{array}$ & $\begin{array}{l}.20 \\
.11\end{array}$ & .06 & 1.38 & .01 \\
\hline Model 3 & $\begin{array}{l}\text { Motor reserve } \\
\text { Education-CRI } \\
\text { Occupation- } \\
\text { CRI }\end{array}$ & $\begin{array}{l}.20 \\
.03 \\
.17\end{array}$ & .08 & 1.22 & .02 \\
\hline Model 4 & $\begin{array}{l}\text { Motor reserve } \\
\text { Education-CRI } \\
\text { Occupation- } \\
\text { Leisure time- } \\
\text { CRI }\end{array}$ & $\begin{array}{l}.43 \\
.06 \\
.26 \\
-.50\end{array}$ & .26 & $3.43^{*}$ & .18 \\
\hline Model 5 & $\begin{array}{l}\text { Motor reserve } \\
\text { Education-CRI } \\
\text { Occupation- } \\
\text { CRI } \\
\text { Leisure time- } \\
\text { CRI } \\
\text { eTIV }\end{array}$ & $\begin{array}{r}.36 \\
.14 \\
.19 \\
-.51 \\
.30\end{array}$ & .34 & $3.98 * * *$ & .08 \\
\hline
\end{tabular}

Note. CRI - Cognitive Reserve Index, eTIV - estimated total intracranial volume, ${ }^{*} p<.05, * * * p<.000$

Model 4 with the addition of leisure led to a significant increase in $R^{2}$ of .18, $F(1,39)=9.30, p<.05$, and finally the model with the addition of eTIV to the prediction of volume of the left side of the thalamus led to a significant increase in $R^{2}$ of $.08, F(1,38)=4.8, p<.04$.

The full model of motor reserve, education, occupation, leisure, and eTIV to predict the volume of the right side of the thalamus (Table 3) was statistically significant, $R^{2}=.43, F(5,38)=5.74, p<.001$. The addition of education to the prediction of volume of the right side of the thalamus (Model2) led to a statistically insignificant increase in $R^{2}$ of $.00, F(1,41)=.05, p>.05$, the addition of occupation to the previous model (Model 3 ), was also a statistically insignificant model giving an increase in $R^{2}$ of $.02, F(1,40)=0.87, p>.05$. The addition of leisure to the module (Module 4) also gave a statistically insignificant increase in $R^{2}$ of $.07, F(1,39)=2.94, p>.05$. And finally, the addition of motor reserve to the module to the prediction of volume of the right side of the thalamus led to a statistically significant increase in $R^{2}$ of .31, $F(1,38)=20.735, p<.001$. 
SOCIETY. INTEGRATION. EDUCATION

Proceedings of the International Scientific Conference. Volume IV, May $28^{\text {th }}-29^{\text {th }}$, 2021. 480-490

Table 3 Hierarchical Multiple Regression Predicting Volume Of Right Side Of Thalamus From Motor Reserve, Education-CRI, Occupation-CRI, Leisure Time-CRI,

\begin{tabular}{|c|c|c|c|c|c|}
\hline \multicolumn{6}{|c|}{ eTIV } \\
\hline \multicolumn{2}{|c|}{ Thalamus-Right } & $\beta$ & $R^{2}$ & $\boldsymbol{F}$ & $\Delta R^{2}$ \\
\hline Model 1 & Motor reserve & 18 & .03 & 1.35 & .03 \\
\hline \multirow[t]{2}{*}{ Model 2} & Motor reserve & .17 & .03 & .69 & .00 \\
\hline & Education-CRI & .04 & & & \\
\hline \multirow[t]{3}{*}{ Model 3} & Motor reserve & .17 & .05 & .75 & .02 \\
\hline & Education-CRI & -.04 & & & \\
\hline & Occupation-CRI & .16 & & & \\
\hline \multirow[t]{4}{*}{ Model 4} & Motor reserve & .31 & .12 & 1.32 & .07 \\
\hline & Education-CRI & -.02 & & & \\
\hline & Occupation-CRI & .22 & & & \\
\hline & Leisure time-CRI & -.31 & & & \\
\hline \multirow[t]{5}{*}{ Model 5} & Motor reserve & .17 & .43 & $5.74 * * *$ & .31 \\
\hline & Education-CRI & .12 & & & \\
\hline & Occupation-CRI & .09 & & & \\
\hline & Leisure time-CRI & -.32 & & & \\
\hline & eTIV & .59 & & & \\
\hline
\end{tabular}

Note. CRI - Cognitive Reserve Index, eTIV-estimated total intracranial volume, ${ }^{* * *} p<.000$

Table 4 Hierarchical Multiple Regression Predicting Total Volume Of Thalamus From Motor Reserve, Education-CRI, Occupation-CRI, Leisure Time-CRI, eTIV

\begin{tabular}{|cl|c|c|c|c|}
\hline & Thalamus & $\boldsymbol{\beta}$ & $\boldsymbol{R}^{\mathbf{2}}$ & $\boldsymbol{F}$ & $\boldsymbol{\Delta R}^{\mathbf{2}}$ \\
\hline Model 1 & Motor reserve & .21 & .05 & 1.99 & .05 \\
\hline Model 2 & Motor reserve & .19 & .05 & 1.11 & .01 \\
& Education-CRI & .08 & & & .02 \\
\hline Model 3 & Motor reserve & .20 & .07 & 1.07 & \\
& Education-CRI & -.01 & & & .13 \\
& Occupation-CRI & .17 & & & \\
\hline Model 4 & Motor reserve & .39 & .20 & 2.50 & \\
& Education-CRI & .03 & & & \\
& Occupation-CRI & .26 & & & \\
& Leisure time-CRI & -.43 & & & \\
\hline Model 5 & Motor reserve & .28 & .39 & $4.87 * * *$ & \\
& Education-CRI & .13 & & & \\
& Occupation-CRI & .15 & & & \\
& Leisure time-CRI & -.44 & & & \\
& eTIV & .46 & & & \\
\hline
\end{tabular}

Note. CRI - Cognitive Reserve Index, eTIV - estimated total intracranial volume, ${ }^{* * *} p<.000$

The full model of the motor reserve, education, occupation, leisure and eTIV to the prediction of the total volume of the thalamus (Table 4) was statistically significant, $R^{2}=.39, F(5,38)=4.87, p=.002$. The addition of education to the prediction of total volume of thalamus led to a statistically insignificant increase 
in $R^{2}$ of $.006, F(1,41)=.26, p>.05$. Then the addition of occupation to Model 2 (motor reserve and education) led to a statistically insignificant increase in $R^{2}$ as well, being $.02, F(1,40)=.99, p>.05$. The model 4 and model 5 respectively with the addition of leisure led to a statistically significant increase in $R^{2}$ of .13 , $F(1,39)=6.37, p<.05$ and adding the eTIV leading to a statistically significant increase in $R^{2}$ of .19, $F(1,38)=11,64, p<.05$.

\section{Discussion}

This study aimed to investigate the relationship between the newly defined motor reserve concept, cognitive reserve, and brain volumetry.

With the increasing worldwide population there is no doubt dementia is taking a toll on the health of the community. With no etiologically effective treatment, prevention is the leading plan for lessening the burden of the disease. Regardless of the increasing amount of research on short-term physical activity and dementia, little is known about the long-term effects.

Overall, our study indicated the significance of a combination of lifestyle factors in predicting thalamic volume. The individual factors themselves did not contribute significantly to the prediction; however, the increase was the most significant when adding leisure time activities. This aspect enhances not only the significance of social relationships and hobbies but also stresses the aspects of cultural heritage, as the scale includes questions on reading, visiting theatres and exhibitions, reading actively, etc. Several studies have shown the relationship between slower age-related cognitive decline and cultural engagement (e.g. visiting museums, theatre, opera), as well as living in culture-respective environments (e.g. as in the case of immigration) (Day \& Cohen, 2000; Douka et al., 2019; Fancourt \& Steptoe, 2018).

The volumetric and microstructural changes in the thalamus correspond with ageing, indicating the significance of older age in the decline (Hughes et al., 2012). Thalamus is often defined as critical regarding the communication between cortical regions not only as a passive relay of information but as an integrator of information processing between regions and is considered to be one of the most cognitively flexible brain regions mediating not only high-level cognitive processes such as attention but simpler sensorimotor functions as well (Hwang et al., 2017).

Among the cognitive functions often associated with the thalamus, are memory, information processing speed (Fama \& Sullivan, 2015), as well as its involvement in linguistic operations. While thalamus is not considered to be directly involved in language processing and production, an ongoing hypothesis indicates a cortico-thalamic language network that indicates the thalamus as a moderator in language execution (Klosterman, Kruger, \& Ehler, 2013). Several 
studies have indicated the role of language in predicting pathological cognitive decline (e.g. The Nun Study). There have been some indications of the role of linguistic abilities in cognitive reserve as well, specifically considering the aspect of bilingualism. A recent review supports the contribution of bilingualism in cognitive reserve (Guzmán-Vélez \& Tranel, 2015), thus the ability to speak many languages might have an implicit effect on volume of the thalamus whilst multilingualism could also be associated with the level of education.

Whilst the research investigating the volume of thalamus in an aspect of physical activity is quite sparse there is some research evaluating the thalamus in the population of known co-morbidities and evaluating the aspect of hippocampus in healthy adults as well. For example, research by Alosco et al. (2015) revealed a significant association between steps per day and the total volume of the thalamus in adults suffering from heart failure. The same research, however, did not see an association in the volume of nucleus caudatus or hippocampus, or amygdala, contrary to many other pieces of research.

Some limitations should be acknowledged in this study. Firstly, due to small sample size, more participants should be considered as more data could show some differences in correlation with both - cognitive reserve and motor reserve, when it comes to brain volumetry. Secondly, due to gender distribution in the sampling size (with female gender representing the greater part of the study) perhaps an analysis between the genders could also offer different data to compare.

To conclude, our study results support previous research indicating the significance of integrating socially, intellectually, and physically active lifestyle not only as a short-term intervention, but also as regular activities all through life. Further studies, allowing to pinpoint specific activity-sensitive periods in life, would be beneficial in both - individual and societal levels.

\section{Acknowledgments}

This study is conducted under the State Research Programme BIOMEDICINE, sub-project No. 5.8.2.

\section{References}

Alosco, M. L., Brickman, A. M., Spitznagel, M. B., Sweet, L. H., Josephson, R., Griffith, E.Y., et al. (2015). Daily Physical Activity Is Associated with Subcortical Brain Volume and Cognition in Heart Failure. Journal of the International Neuropsychological Society: JINS, 21(10), 851-860. DOI:https://doi.org/10.1017/S1355617715000697 
Bartrés-Faz, D., \& Arenaza-Urquijo, E. M. (2011). Structural and functional imaging correlates of cognitive and brain reserve hypotheses in healthy and pathological aging. Brain topography, 24(3-4), 340-357. DOI:https://doi.org/10.1007/s10548-011-0195-9

Bherer, L., Erickson, K. I., \& Liu-Ambrose, T. (2013). A review of the effects of physical activity and exercise on cognitive and brain functions in older adults. Journal of aging research, 2013, 657508. DOI:https://doi.org/10.1155/2013/657508

Biazus-Sehn, L.F., Schuch, F.B., Firth, J., Stigger, F.S. (2020). Effects of physical exercise on cognitive function of older adults with mild cognitive impairment: A systematic review and meta-analysis. Arch Gerontol Geriatr. 2020 Jul-Aug;89:104048. DOI: 10.1016/j.archger.2020.104048.

Boots, E. A., Schultz, S. A., Oh, J. M., Larson, J., Edwards, D., Cook, D., et al. (2015). Cardiorespiratory fitness is associated with brain structure, cognition, and mood in a middle-aged cohort at risk for Alzheimer's disease. Brain imaging and behavior, 9(3), 639-649. DOI:https://doi.org/10.1007/s11682-014-9325-9

Caspersen, C. J., Powell, K. E., \& Christenson, G. M. (1985). Physical activity, exercise, and physical fitness: definitions and distinctions for health-related research. Public health reports (Washington, D.C. : 1974), 100(2), 126-131.

Colcombe, S. J., Erickson, K. I., Scalf, P. E., Kim, J. S., Prakash, R., McAuley, et al. (2006). Aerobic exercise training increases brain volume in aging humans. The journals of gerontology. Series A, Biological sciences and medical sciences, 61(11), 1166-1170. DOI:https://doi.org/10.1093/gerona/61.11.1166

Day, K., \& Cohen, U. (2000). The Role of Culture in Designing Environments for People with Dementia. Environment and Behavior, 32(3), 361-399. DOI: https://doi.org/ 10.1177/00139160021972577

Douka, S., Zilidou, V. I., Lilou, O., \& Manou, V. (2019). Traditional dance improves the physical fitness and well-being of the elderly. Frontiers in Aging Neuroscience, 11(APR). DOI: https://doi.org/10.3389/fnagi.2019.00075

Erickson, K. I., Voss, M. W., Prakash, R. S., Basak, C., Szabo, A., Chaddock, et al. (2011). Exercise training increases size of hippocampus and improves memory. Proceedings of the National Academy of Sciences of the United States of America, 108(7), 3017-3022. DOI: https://doi.org/10.1073/pnas.1015950108

Fama, R., \& Sullivan, E. V. (2015). Thalamic structures and associated cognitive functions: Relations with age and aging. Neuroscience \& Biobehavioral Reviews, 54, 29-37. DOI: 10.1016/j.neubiorev.2015.03.008

Fancourt, D., \& Steptoe, A. (2018). Cultural engagement predicts changes in cognitive function in older adults over a 10 year period: Findings from the English Longitudinal Study of Ageing. Scientific Reports, 8(1), 10226. https://doi.org/10.1038/s41598-018-28591-8

Frith, E., \& Loprinzi, P. D. (2018). Physical activity is associated with higher cognitive function among adults at risk for Alzheimer's disease. Complementary therapies in medicine, 36, 46-49. DOI: https://doi.org/10.1016/j.ctim.2017.11.014

Guzmán-Vélez, E., \& Tranel, D. (2015). Does bilingualism contribute to cognitive reserve? Cognitive and neural perspectives. Neuropsychology, 29(1), 139-150. DOI: https://doi.org/10.1037/neu0000105

Hughes, E. J., Bond, J., Svrckova, P., Makropoulos, A., Ball, G., Sharp, D. J., et al. (2012). Regional changes in thalamic shape and volume with increasing age. Neuroimage, 63(3), 1134-1142. DOI: 10.1016/j.neuroimage.2012.07.043 
Hwang, K., Bertolero, M. A., Liu, W. B., \& D'esposito, M. (2017). The human thalamus is an integrative hub for functional brain networks. Journal of Neuroscience, 37(23), 55945607. DOI: 10.1523/JNEUROSCI.0067-17.2017

Nucci, M., Mapelli, D., \& Mondini, S. (2012). Cognitive Reserve Index questionnaire (CRIq): a new instrument for measuring cognitive reserve. Aging clinical and experimental research, 24(3), 218-226. DOI: https://doi.org/10.3275/7800

O'Brien, L. M., Ziegler, D. A., Deutsch, C. K., Frazier, J. A., Herbert, M. R., \& Locascio, J. J. (2011). Statistical adjustments for brain size in volumetric neuroimaging studies: some practical implications in methods. Psychiatry Research: Neuroimaging, 193(2), 113-122. DOI: 10.1016/j.pscychresns.2011.01.007

Prakash, R. S., Snook, E. M., Motl, R. W., \& Kramer, A. F. (2010). Aerobic fitness is associated with gray matter volume and white matter integrity in multiple sclerosis. Brain research, 1341, 41-51. DOI: https://doi.org/10.1016/j.brainres.2009.06.063

Pudule I., Villeruša A., Grīnberga D., Velika B., Tilgale N., Dzērve V., et al. (2010). Health Behaviour among Latvian Adult Population, 2008. Pieejams: http://petijumi.mk.gov.lv/ sites/default/files/title_file/Petijums_2008_Latvijas_iedzivotaju_veselibu_ietekmejoso_ paradumu_petijums.pdf

Rocca, M. A., Riccitelli, G. C., Meani, A., Pagani, E., Del Sette, P., Martinelli, V., et al. (2019). Cognitive reserve, cognition, and regional brain damage in MS: A 2 -year longitudinal study. Multiple sclerosis (Houndmills, Basingstoke, England), 25(3), 372-381. DOI: https://doi.org/10.1177/1352458517750767

Šneidere, K., Alruwais, N., Dowell, N. G., Arnis, V., Harlamova, J., Kupčs, K., et al. (2019). Differences in Long- and Short-Term Memory Performance and Brain Matter Integrity in Seniors With Different Physical Activity Experience, Proceedings of the Latvian Academy of Sciences. Section B. Natural, Exact, and Applied Sciences., 73(2), 158-163. DOI: https://doi.org/10.2478/prolas-2019-0025

Speer, M. E., \& Soldan, A. (2015). Cognitive reserve modulates ERPs associated with verbal working memory in healthy younger and older adults. Neurobiology of Aging, 36(3), 1424-1434. DOI: https://doi.org/10.1016/J.NEUROBIOLAGING.2014.12.025

Spirduso, W. W. (1975). Reaction and movement time as a function of age and physical activity level. Journal of gerontology, 30(4), 435-440. DOI: https://doi.org/10.1093/ geronj/30.4.435

Stern, Y., Arenaza-Urquijo, E. M., Bartrés-Faz, D., Belleville, S., Cantilon, M., Chetelat, G., et al. (2018). Whitepaper: Defining and investigating cognitive reserve, brain reserve, and brain maintenance. Alzheimer's and Dementia, 1-7. DOI: https://doi.org/10.1016/ j.jalz.2018.07.219

World Alzheimer Report. (2015). The Global Impact of Dementia. Retrieved from: https://www.alzint.org/u/WorldAlzheimerReport2015.pdf

World Health Organization. (2015). World report on ageing and health. Retrieved from: https://www.who.int/ageing/events/world-report-2015-launch/en/

Young, J. C., Dowell, N. G., Watt, P. W., Tabet, N., \& Rusted, J. M. (2016). Long-Term HighEffort Endurance Exercise in Older Adults: Diminishing Returns for Cognitive and Brain Aging. Journal of Aging and Physical Activity, 24(4), 659-675. DOI: https://doi.org/10.1123/japa.2015-0039 